\title{
Penyuluhan Gaya Hidup Sehat Melalui Aktivitas Jasmani Bagi Masyarakat Di Komplek Kharismatama Permai Kelurahan Batang Kabung Kecamatan Koto Tangah Kota Padang
}

\author{
Ali mardius ${ }^{1 *}$, Yuni Astuti ${ }^{2}$ \\ 1,2,Program Studi Pendidikan Jasmani Kesehatan dan Rekreasi Fakultas Keguruan dan Ilmu Pendidikan Universitas Bunghatta
}

\section{A R T I C L E I N F O}

\section{Article history:}

Received 19 August 2018 Received in revised form 12 September 2018 Accepted 28 Oktober 2018 Available online 25 November 2018

\section{Kata Kunci:}

Gaya hidup sehat

Keywords:

Healthy lifestyle
A B S T R A K

Permasalahan yang dihadapi oleh masyarakat di Komplek Kharismatama Permai Kelurahan Batang Kabung Kecamatan Koto Tangah Kota Padang yang berjumlah 20 orang yaitu sering mengalami keluhan fisik seperti kram di kaki kalau terlalu lama duduk, kelelahan setelah beraktifitas ringan, mudah sakit karna pergantian cuaca yang terkadang dapat menghambat aktivitas pekerjaan dan lebih memilih untuk tidak keluar rumah. Untuk mengatasi permasalahan tersebut perlunya dilakukan aktifitas jasmani yang mengutamakan kelenturan kaki harus rutin dilakakukan seperti menggetar-getarkan, meregangkan serta melemaskannya. Efek dari aktifitas jasmani sederhana ini juga dapat meningkatkan kerja jantung dan paru. Metode yang digunakan yaitu menggunakan metode ceramah dengan media audio visual serta berdiskusi dengan masyarat tentang gerakan yang dilakukan dalam video tersebut tentang aktivitas jasmani yang dapat dilakukan oleh masyarakat. Dari hasil pelaksanaan penyuluhan tersebut dapat diambil kesimpulan bahwa melalui aktivitas jasmani yang dilakukan masyarakat sebagai peserta pengabdian kepada masyarakat yang dilakukan dapat terlaksana dengan baik. Hal tersebut ditandai dengan adanya kesungguhan dan antusiasme untuk bertanya dan diskusi dari peserta pelatihan dan untuk mengetahui bagaimana gerakan gerakan-gerakan sehat melalui aktivitas jasmani.

\section{A B S T R A C T}

Problems faced by the community in the Kharismatama Permai Complex in Batang Kabung Village, Koto Tangah Subdistrict, Padang City, amounting to 20 people complaints such as cramps in the legs if too long sitting, fatigue after activity, easyly sick because of weather shifts that can also hamper work activities and most people choose stay at home. To solving these problems we need physical activity for flexibility of the feet should be routinely like vibrating, stretching and relaxed. The effects of this simple physical activity can also improve the work of the heart and lungs. The method used is lecture method with audio visual than discuss with community about physical activity which can be done by society. The results of the implementation of the counseling can be concluded that through the physical activity of the community as by participant of service performed can be done well. It's marked by the seriousness and enthusiasm of community to ask questions and discussions with the trainees and to find out how the movement of healthy movements through physical activity.

\footnotetext{
* Corresponding author.

E-mail addresses: yuniastuti@bunghatta.ac.id (Yuni Astuti), alimardius@bunghatta@ac.id (Ali Mardius)
} 


\section{Pendahuluan}

Perkembangan teknologi yang tepat guna atau lowcost (biaya rendah) mengakibatkan kurangnya aktifitas gerak manusia, karna masyarakat sekarang lebih cendrung menggunakan fasilitas-fasilitas keseharian yang di kerjakan oleh mesin. Tanpa menggunakan jasmani seperti berjalan, berlari, mencuci dan sebagainya. Apa lagi kegiatan perkantoran yang cendrung duduk seharian dalam ruangan yang ber AC. Hal ini tentu akan memberikan efek yang tidak bagus pada jasmani baik kaum bapak-bapak maupun ibu-ibu yang sudah berumur di atas empat puluh tahun. Keadaan seperti ini apabila di biarkan maka organ-organ tubuh akan lemah dan kesehatan dan kebugaran tubuh akan terganggu (Wibawa, 2013). Kesehatan merupakan hak dasar manusia dan merupakan salah satu faktor yang sangat menentukan kualitas sumber daya manusia dengan mencanangkan visi Indonesia sehat 2010 (Sani, 2011). Sehat dapat diartikan sebaga keadaan baik seluruh tubuh serta bagianbagiannya atau suatu hal yang menimbulkan kebaikan, sedangkan kesehatan sendiri dapat diartikan sebagai keadaan sehat yang terbebas dari penyakit dan kebaikan keadaan badan (Utama,2016). Gaya hidup yang tidak sehat, dapat menyebabkan terjadinya penyakit hipertensi, misalnya; makanan, aktifitas fisik, stres, dan merokok (Suoth, 2014). Gaya hidup adalah konsep yang lebih baru dan lebih mudah terukur dibandingkan dibandingkan dengan kepribadian (Listyorini, 2012). Gaya Hidup Sehat menyangkut aturan untuk mencapai kesehatan jasmani dan rohani yaitu dengan cara mengatur pola makan dan kebiasaaan untuk memakan makanan sehat, menjauhi gula dan memperbanyak makan sayur dan buah (Paramita, 2014).

Suharno (2008) menjelaskan bahwa "sehat atau bugar adalah kemampuan tubuh untuk melakukan aktivitas dalam waktu yang lama tanpa mengalami kelehan yang berarti dan masih tersimpan tenaga untuk hal-hal yang sifatnya darurat (emergency)". Sementara itu Syafruddin (2011) mengemukan bahwa "sehat itu adalah tidak ada keluhan pada jasmani". Ada beberapa cara aktivitas jasmani yang bisa dilakukan, tergantung pada tujuan dan situasinya, misalnya jogging, bersepeda dan sebagainya. Pada kesempatan ini akan di sajikan salah satu jenis aktivitas jasmani ringan dan murah namun hasilnya dapat membuat jasmani menjadi sehat/bugar dan ini sangat cocok untuk masyarat sibuk dengan pekerjaan dan tugas rutin sehingga tidak ada waktu khusus untuk beraktivitas jasmani. Menurut Mardius Ali dan Astuti Yuni (2017:147) menyampaikan bahwa "Pentingnya kebugaran jasmani yang baik untuk menunjang aktivitas kerja terutama masyarakat yang sudah memasuki usia lanjut yang".

Bahkan bagi yang sakitpun bisa melakukan sebagai terapi karena beban bobot latihannya tergantung pada kemampuan masing-masing individu. Aktivitas jasmani ini tidak mmbutuhkan alat dan ruangan yang luas, dapat di lakukan di teras rumah, ruang tamu dan juga bisa di lakukan di dalam kamar dengan waktu antara 20-30 menit, sehinggga tidak terpengaruh akan gangguan hujan ataupun panas matahari, aktivitas jasmani ini dapat dilakukan pagi menjelang mandi dan sore dan kapan saja ada waktu.

Inti gerakan pada aktifitas jasmani ini adalah bagaimana memungsikan semua persndian dengan sempurna (maksimal), sehingga bisa menarik otot-otot tubuh menjadi lentur dan terhindar dari ketegangan atau kejang otot. Apabila otot-otot lentur, maka pembuluh-pembuluh darah (arteri) yang ada sekitarnya tidak terjepit dan peredaran darah (arteri) menjadi lancar. Arteri ini berfungsi mengirim oksigen (02) yang di gunakan untuk pembajkaran (oksidasi) di sel-sel tubuh untuk menghasilkan energi dan panas. Renergi digunakan untuk aktivitasdan selanjutnya sisa pembakaran berupa carbon dioksida (CO2) diangkut melaui pembuluh balik (Vena) kembali ke jantung dan diteruskan ke paru-paru untuk di bersihkan (CO2 dibuang melalui hembusan napas). Apabila proses itu lancar diharapkan masyarakat dalam keadaan sehat, rasa segar/bugar yang dirasakan setiap saat, Husdarta (2010).

\section{Metode}

Pengabdian mayarakat ini dilakukan pada bulan maret - april tahun 2018 di komplek kharismata permai kelurahan Batang kabung kecematan kota Tangah Padang. Upaya yang dilakukan adalah dengan memberikan sejumlah materi yang relefan sesuaia dengan masalah yang sesuai dengan target serta luaran yang diinginkan dalam penelitian ini maka metode pendekatan pendekatan yang lingkungan yang dilakukan dalam kegiatan ini adalah dengan dengan metode :

1. Metode Ceramah: Metode ini digunakan untuk memberikan pemahaman yang lengkap kepada para peserta tentang suatu topik. Dalam ceramah diuraikan kerangka materi secara lengkap, jelas, mudah dipahami, dan aplikatif. Metode ceramah dalam workshop ini di gampilkan melalu power poin dan diusahakan untuk menghindari pembahasan teoritis yang berlarut-larut dan lebih menekankan pada contoh-contoh kasus beserta pemecahannya.

2. Metode tanya jawab atau diskusi yang dilakukan untuk membahas terkait berbagai hambatan dan atau masalah yang dihadapi dalam kehidupan sehari-hari sehingga dapat menjalani hidup dalam keadaan sehat melalui aktifitas fisik. Diskusi dipilih untuk lebih memberikan kesempatan kepada para peserta: 
membahas, mempertanyakan, menggaris bawahi, memberikan masukan, dan memperdalam materi yang disampaikan.

3. Selanjutnya metode yang digunakan yaitu metode pelatihan. Arti dari metode pelatihan ini adalah memberikan peragaan atau praktek secara langsung bagaimana melakukan gerakan - gerakan mulai dari tidur, gerakan waktu duduk dan gerkan pada waktu berdiri. Berikut Beberapa keterampilan yang diajarkan kepada peserta pengabdian adalan sebagai berikut:

Persia pan

1) Lantai datar dilapisi karpet atau tikar berukuran lebih kurang $2 \times 3$ meter. Di tempat tidurpun bisa dilakukan.

2) Posisi tidur telentang, kedua tangan di samping badan, dalam keadaan rileks (santai)

a)Gerakan pada posisi duduk : 1) Angkat kedua kaki tegak lurus sejajar, getarkan kedua kaki bersamaan atau bergantian, sehingga kaki terasa bergetar, 2) Tekuk kedua kaki dengan menekuk lutut secara bersamaan atau bergantian, perlahan-lahan seenaknya (rileks), 3) Luruskan lagi kedua kaki, getarkan lagi kedua kaki bersamaan atau bergantian sampai terasa kaki bergetar, 4) Tekuk lagi kedua kaki seperti, diulang-ulang sampai merasakan perkenaan tumit pada pantat dengan mudah (rileks), 5) Luruskan lagi kedua kaki Tekuk lagi kedua kaki dan getarkan. Begitu seterusnya gerakan diulang-ulang sampai otot-otot betis dan paha terasa lentur dan sendi-sendi pada kedua kaki dapat berfungsi dengan baik.

b) Gerakan pada posisi duduk. Setelah gerakan pada posisi tidur telentang dilakukan, dilanjutkan gerakan pada posisi duduk tegak dengan kedua kaki telunjur rileks dan kedua tangan di samping badan: 1) Putarlah kepala dengan sempurna (diikuti pandangan kedua mata), ke arah kiri-bawah, kiri atas, kanan atas, kanan bawah, kiri bawah beberapa kali, kemudian bergantian arah, dan seterusnya, sehingga betul-betul terasa kepala ini berputar dengan nyaman (enak), 2) Selanjutnya, getarkan kedua pergelangan tangan dengan rileks, baik dalam posisi tangan tengadah maupun tangan telungkup, 3) Gerakkan otot-otot persendian bahu dan siku dengan rileks

c) Gerakan pada waktu berdiri: 1) Dalam posisi berdiri ini dapat dilakukan gerakan lari-lari kecil disertai angkat paha di tempat, dan tetap mengikuti prinsip gerakan rileks sambil menggetar-getarkan persendian, 2) Ayunkan kedua lengan kiri kanan secara bergantian sebagaimana gerakan lari dengan memungsikan sendi bahu dan lutut dengan maksimal.

Demikianlah gerakan dimulai pada posisi tidur telentang, posisi duduk,dan posisi berdiri dilakukan berulang-ulang secukupnya sampai sendi-sendi terasa lentur dan badan berkeringat Gerakan ini bisa dilakukan di mana dan kapan saja tergantung pada kesempatan kita masing-masing. Jika dilakukan secara rutin, tentu (InsyaAllah) hasilnya badan menjadi sehat, segar dan mudah di lakukan.

\section{Hasil dan pembahasan}

Dari hasil diskusi awal tim pelaksana dari penyiapan materi pelatihan dengan memberikan penjelasan yang di sertakan dengan gambar serta video bagaimana cara melakukan gerakan - gerkan aktivitas jasmani mulai dari terlentang, duduk dan berdiri. Sehingga setelah peserta mendengarkan penjelasan dan praktek dari video maka peserta dapat melakukan praktek sendiri. Selama proses pelatihan tim pelaksana pengabdian selalu melakukan pemantauan kepada peserta dan respon yang diberikan secara umum oleh masyakat dalam hal ini warga peserta pelatihan mengatkan bahwa pelatihan ini sangat bermanfaat walaupun di awal memang agak sedikit berat karna otot- otot banyak yang kaku, tetapi berlahan - lahan badan terasa ringan dan kaki biasanya kram kalau duduk lama mulai agak kurang karna efek dari gerakan yang di lakukan.

Peserta pengabdian kepada masyarakat tentang gaya hidup sehat melalui aktivitas jasmani ini berjumlah 30 orang warga di komplek kharismatama permai kelurahan Batang Kabung Kota Padang. Sebagian dari peserta pelatihan sudah melakukan gerakan-gerakan aktivitas olahraga di pagi hari tapi yang rutin yang di lakukan adalah jalan pagi dan itupun hanya di sekitar komplek saja namun karna tidak ada yang memberikan bimbingan tentang bagiamana bentuk aktivitas yang baik dan keteraturan bergerak mulai dari persiapan termasuk cek denyut nadi, pelaksanaan dan pendinginan, karna sering terjadi kesalahan dan terkadang hasil yang di dapat selama ini kurang meringankan badan atau mendapatkan kebugaran karna ada beberapa syarat yang di tinggalkan terutama persiapan maka setelah melakukan pelatihan warga kharismatama yang menjadi peserta antusias dan lansung bertanya kalau seandainya ada di ragukan dari pernyataan dan contoh gerakan yang di praktekkan.

Berdasarkan pelaksanaan penerapan ipteks bagi masyarakat yang berjudul penyuluhan gaya hidup sehat melalui aktivitas jasmani bagi masyarakat di komplek kharismatama permai kelurahan Batang Kabung Kecematan koto Tangah Kota Padang. Maka hasil yang dicapai dideskripsikan yaitu sebagai berikut: 
Menambah wawasan pengetahuan teori maupun praktik tentang penyuluhan gaya hidup sehat melalui aktivitas jasmani, sehingga dapat bermanfaat untuk mendapatkan kesehatan dan kebugaran oleh masyarakat.

Meningkatnya kesehatan dan kebugaran masyarakat yang dapat memberikan efek untuk menghilangkan kram otot, cardio vaskuler (jantung) dan cardio respiratori (paru), pembuluh darah, serta mempercepat mengembalikan kondisi tubuh.

Berdasarkan gambar dan video yang diberikan kepada peserta pengabdian kepada masyarakat tentang penyuluhan gaya hidup sehat melalui aktivitas jasmani tersebut, maka setelah pengarahan dan penjelasan secara teori peserta pelatihan langsung mempraktekkan gerakan-gerakan ini dengan baik dan benar. Walaupun gerakannya masih ada yang belum sesuai dengan teknik yang sebenarnya.

Pada tahapan selanjutnya yang akan dilakukan yaitu memberikan pengetahuan dan keterampilan tentang bagaimana melaksanakan aktivitas jasmani dengan gerakan-gerakan dengan intersitas yang lebih tinggi dan teknik yang lebih halus sehingga gerakan yang di lakukan lebih pada penguatan otot sehingga lebih tahan dan lebih efektif dalam bekerja. Jadi setiap gerakan yang di lakukan dapat di pahami dan memang di jadikan kebutuhan hidup sehari-hari sama halnya dengan kebutuhan makan dalam kelansungan hidup, sama halnya kebutuhan otot, jantung dan paru yang di butuhkan adalah penguatan ototnya dengan gerakan-gerakan yang teratur dan benar.

Penerapan ipteks bagi masyarakat tentang penyuluhan gaya hidup sehat melalui aktivitas jasmani ini mempunyai beberapa target, diantaranya adalah:

Terjadinya peningkatan pengetahuan tentang ilmu massage pada warga di Komplek kharismatama Permai Kelurahan Batang kabung Kecamatan Koto Tangah Kota Padang.

Terjadinya peningkatan kualitas jasmani warga komplek kharismatama kelurahan Batang kabung Kota Padang, sehinga warga dapat menjadi sehat dan bugar serta mampu menguasai gerakan-gerakan melaui aktivitas kebugaran untuk menjaga dan meningkatkan kualitas jasmani untuk lebih bagus lagi.

\section{Simpulan dan saran}

Penyuluhan gaya hidup sehat melalui aktivitas jasmani yang dilakukan warga sebagai peserta pengabdian kepada masyarakat yang dilakukan dapat terlaksana dengan baik. Hal tersebut ditandai dengan adanya kesungguhan dan antusiasme untuk bertanya dan diskusi dari peserta pelatihan dan untuk mengetahui bagaimana gerakan gerakan-gerakan sehat melalui aktivitas jasmani Inti gerakan adalah : Tekuk - lurus - getarkan, tekuk - lurus - getarkan, dan seterusnya diulang-ulang.

Adapun saran yang disampaikan pada penelitian ini adalah agar para warga mulai hidup sehat dengan olahraga. Meningkatkan keantusiasan dalam mengikuti penyuluhan tentang gaya hidup sehat agar gaya hidup sehat melalui aktivitas jasmani dapat dijadikan sebagai budaya dalam masyarakat.

\section{Daftar Rujukan}

Adliyani, Zaraz Obella Nur. 2015. Pengaruh Perilaku Individu terhadap Hidup Sehat. Medical Journal Of Lampung University, Vol.4, No.7.

Emilia, Esi. 2009. Pengetahuan, Sikap Dan Praktek Gizi Pada Remaja Dan Implikasinya Pada Sosialisasi Perilaku Hidup Sehat. Media Pendidikan, Gizi dan Kuliner, Vol.1, No.1.

Husdarta. (2010). PsikologiOlahraga. Bandung: Alfabeta.

Listyorini,Sari. 2012. Analisis Faktor- Faktor Gaya Hidup Dan Pengaruhnya Terhadap Pembelian Rumah Sehat Sederhana (Studi Pada Pelanggan Perumahan Puri Dinar Mas PT. Ajisaka Di Semarang). Jurnal Administrasi Bisnis, Vol.1, No.1.

Mardius Ali dan Astuti Yuni (2017). Pengaruh Senam Lansia Terhadap Kebugaran Jasmani Warga Perumahan Pondok Pinang Kelurahan Lubuk Buaya Kecamatan Koto Tangah Kota Padang. Journal of Education Research and Evaluation. Vol.1 (3) pp. 147-152.

Paramitha,Novena Mayayu. 2014. Pengaruh Gaya Hidup Sehat Untuk Mengatasi Turnover Intentions Yang Terjadi Di Akuntan Publik. Jurnal Akuntansi Bisnis, Vol.8, No.25.

Roni, Tatang dkk. 2013. Hubungan Pendidikan dan Penghasilan Dengan Perilaku Hidup Bersih dan Sehat. Jurnal Kesehatan Lingkungan Indonesia. Vol.12, No.1. 
Sani,Fakhrudin Nasrul. 2011. Hubungan Tingkat Pengetahuan Sehat - Sakit Dengan Sikap Mahasiswa Universitas Muhammadiyah Surakarta Tentang Perilaku Hidup Bersih Dan Sehat. Jurnal Kesehatan Kusuma Husada, Vol.2, No.2.

Suoth,Meylen dkk. 2014. Hubungan Gaya Hidup Dengan Kejadian Hipertensi Di Puskesmas Kolongan Kecamatan Kalawat Kabupaten Minahasa Utara. Jurnal Keperawatan, Vol.2, No.1.

Suharno. (2009). Latihan Jasmani dalam Pencegahan Penyakit Jantung Koroner. Jakarta: Salemba Media.

Syafruddin. (2011). Ilmu Melatih Dasar. Padang: UNP Press.

Utama,Rizky Septyan Karya. 2016. Perbandingan Perilaku Hidup Sehat Antara Siswa SMPN 1 Badas Dengan Siswa MTs Mashlahiyah Krecek Kabupaten Kediri. Jurnal Pendidikan Olahraga dan Kesehatan, Vol.4, No.1.

Wahyuni,Endang Sri dkk. 2007. Faktor-Faktor Yang Berhubungan Dengan Perilaku Pembaca Dalam Memperoleh Informasi Gaya Hidup Sehat (Studi kasus Pembaca Tabloid Senior di Kecamatan Bogor Utara). Jurnal Penyuluhan, Vol.3, No.2.

Wibawa,Nyoman Adi Krisna dan Putu Nugrahaeni Widiasavitri. 2013. Hubungan antara Gaya Hidup Sehat dengan Tingkat Stres Siswa Kelas XII SMA Negeri di Denpasar Menjelang Ujian Nasional Berdasarkan Strategi Coping Stres. Jurnal Psikologi Udayana, Vol.1, No.1. 